01.1;03.1

\title{
Двумерное моделирование ослабления детонационной волны при ее прохождении через область с круговыми препятствиями
}

\author{
(C) И.А. Бедарев, В.М. Темербеков \\ Институт теоретической и прикладной механики им. С.А. Христиановича СО РАН, \\ Новосибирск, Россия \\ E-mail: bedarev@itam.nsc.ru
}

Поступило в Редакцию 24 ноября 2020 г.

В окончательной редакции 25 марта 2021 г.

Принято к публикации 9 апреля 2021 г.

Представлены результаты численного моделирования взаимодействия детонационной волны с круговыми препятствиями, расположенными в шахматном порядке. Расчеты проводились для подготовленной стехиометрической водородно-воздушной смеси. Исследовано влияние количества рядов, шага между ними и масштабных эффектов на подавление детонации. Получены различные режимы ослабления и реинициирования детонации.

Ключевые слова: детонация, подавление, численные методы, водородно-воздушная смесь.

DOI: 10.21883/PJTF.2021.14.51178.18627

В настоящее время актуален вопрос использования высокоэффективных газообразных топлив для различных энергетических установок. Из-за высокого тепловыделения при окислении горючих газов существует опасность возникновения чрезвычайных ситуаций при их эксплуатации. Аварии с выбросом газообразного горючего зачастую приводят к пожарам и взрывам, в связи с чем большой интерес вызывают исследования, связанные с вопросами взрыво- и пожаробезопасности, в частности работы, направленные на выявление возможности ослабления и подавления газовой детонации, ее инициирования и взаимодействия с различными препятствиями.

Уже имеется ряд работ, в которых исследовалось ослабление детонации, например, облаком инертных частиц [1-3], спиральными препятствиями [4], рядами цилиндров [5]. Внимания также заслуживают работы, связанные с инициированием горения и детонации. Так, в работе [6] изучено влияние препятствий на самовозгорание водорода. В [7] рассмотрено ускорение пламени в каналах с препятствиями. В [8] исследовался механизм инициирования детонации при помощи взаимодействия потока водородно-воздушной смеси с препятствиями.

Целью настоящей работы является разработка численного алгоритма для задачи о взаимодействии детонационной волны с круговыми препятствиями. На основании полученных результатов предполагается сделать первоначальные выводы о возможности подавления детонации в водородно-воздушной смеси, а также определить критерии успешной реализации данного подхода. Ранее была довольно подробно исследована задача о взаимодействии ударных волн с частицами (например, в работе [9]).

В расчетной области (рис. 1) задавалась предварительно перемешанная стехиометрическая смесь водорода и воздуха с параметрами $T_{s t}=300 \mathrm{~K}$ и $P_{s t}=100 \mathrm{kPa}$. Перед препятствиями в качестве начальных условий задавалась предварительно рассчитанная ячеистая детонация. Скорость фронта детонационной волны составляла примерно $1950 \mathrm{~m} / \mathrm{s}$. Диметр окружностей, количество рядов препятствий и шаг между ними варьировались.

Двумерная задача решалась в плоской симметричной постановке в расчетном пакете программ ANSYS Fluent. В рамках математической модели применялись осредненные по Фавру уравнения Навье-Стокса для многокомпонентной газовой смеси. Использовалась приведенная кинетическая схема химической реакции горения водорода в воздухе [10]. Система уравнений дополнялась SST-модификацией $k-\omega$-модели турбулентности [11]. Для аппроксимации по времени использовалась неявная схема второго порядка, для пространственной аппроксимации - противопотоковая схема второго порядка, метод расщепления вектора потока - AUSM. Адекватность выбранной математической модели была продемонстрирована на примере задачи о формировании режимов наклонной детонации [12].

Предполагается, что для успешного подавления детонации необходимо обеспечить достаточную длину участка $L$, в котором расположено препятствие, а также пропускную способность зоны препятствий $\sigma_{n}$. Возрастание $L$ и уменьшение $\sigma_{n}$ способствуют ослаблению

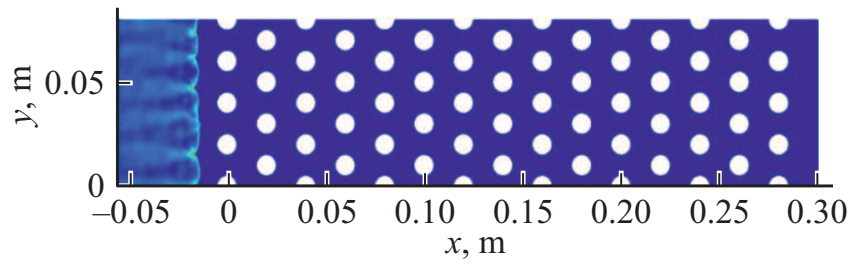

Рис. 1. Расчетная область. 

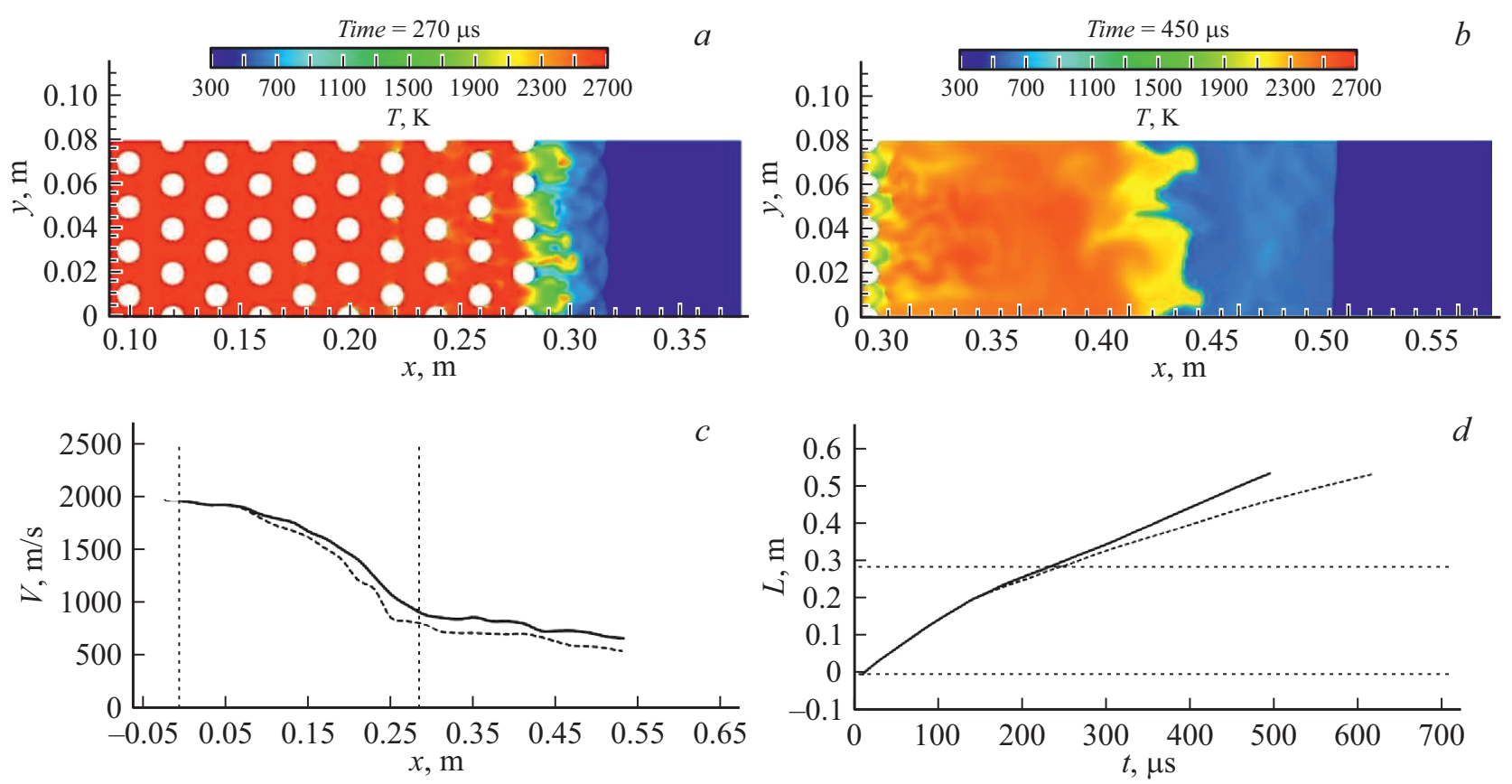

Рис. 2. Результаты расчета для 15 рядов, $d=10 \mathrm{~mm}$ и $h=10 \mathrm{~mm}$. Поля температуры в различные моменты времени $(a, b)$, изменение скоростей фронта ударной волны (сплошные линии) и фронта продуктов реакции (штриховые линии) от продольной координаты $(c)$, положение фронта ударной волны и фронта продуктов реакции в зависимости от времени $(d)$.

детонации. Также известно, что на ослабление, срыв и подавление детонации влияют диаметр окружностей $d$ и расстояние между ними $h$, отнесенные к размеру детонационной ячейки смеси [5]. Под срывом детонации подразумевается разделение фронта детонации на фронт ударной волны и фронт горения. После выхода этой двухфронтовой структуры за границу зоны препятствий возможно реинициирование детонации. В том случае, если реинициирования не происходит, можно говорить о подавлении детонационной волны.

Для диаметра цилиндров $d=10 \mathrm{~mm} \quad$ с шагом $h=10 \mathrm{~mm}$ срыв детонации осуществляется при длине зоны препятствий $L=190 \mathrm{~mm}$ (10 рядов), однако температура и давление за фронтом ударной волны способствуют воспламенению смеси, в результате чего детонация реинициируется. При длине участка $L=285 \mathrm{~mm}$ для 15 рядов препятствий (рис. 2) ударная волна ослабляется настолько, что температура и давление за фронтом ударной волны становятся ниже третьего предела воспламенения водорода в воздухе, и реинициирования детонации не происходит. На рис. 2, $c$ представлен график изменения скорости фронта ударной волны и фронта продуктов реакции по мере прохождения детонационной волны по расчетной области, а на рис. $2, d-$ положение фронта ударной волны и фронта продуктов реакции в зависимости от времени; прямыми пунктирными линиями отмечены границы области препятствия. В данном случае пропускная способность препятствия составляет $\sigma_{n}=80 \%$. При этом диаметр окружностей и расстояние между ними сопоставимы с поперечным размером детонационной ячейки смеси $(\lambda=10-15 \mathrm{~mm})$.
Как указывалось выше, для значительного ослабления детонации помимо протяженности зоны препятствия и его пропускной способности важную роль играет отношение диаметра окружностей и шага между ними к размеру детонационной ячейки смеси. Поэтому в последующем расчете вся решетка была пропорционально увеличена в 2 раза. При этом диаметр составил $d=20 \mathrm{~mm}$, пропускная способность не изменилась, шаг между рядами составил $h=20 \mathrm{~mm}$, а протяженность препятствия достигла величины $L=570 \mathrm{~mm}$. В данном случае, несмотря на увеличение длины участка, при той же пропускной способности не удалось добиться срыва детонации (рис. 3). Для данного случая диаметр окружностей и шаг между ними превышают поперечный размер детонационной ячейки в $1.5-2$ раза.

Моделирование позволяет подтвердить вывод, что на ослабление детонации решающее влияние оказывает отношение диаметра препятствий и шага между ними к размеру детонационной ячейки в смеси.

В работе численно исследована задача о взаимодействии детонационной волны с жесткой проницаемой преградой в водородно-воздушной смеси на основе пакета программ ANSYS Fluent. Выявлено, что для уменьшения скорости детонационной волны от $V=1950$ до $860 \mathrm{~m} / \mathrm{s}$ и вырождения детонационной волны в ударную в стехиометрической водородно-воздушной смеси при атмосферном давлении достаточно 15 рядов круговых препятствий диаметром $10 \mathrm{~mm}$. При этом расстояние между препятствиями составляет $10 \mathrm{~mm}$, а длина зоны препятствий $285 \mathrm{~mm}$. Волна продуктов реакции продолжает 


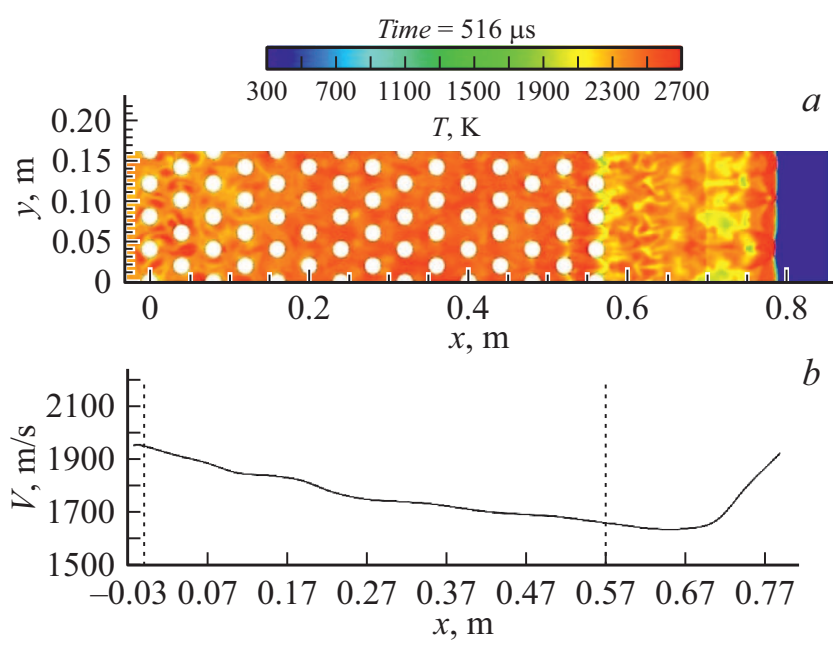

Рис. 3. Результаты расчета для 15 рядов, $d=20 \mathrm{~mm}$ и $h=20 \mathrm{~mm}$. Поля температуры в различные моменты времени (a) и изменение скорости фронта ударной волны в зависимости от продольной координаты $(b)$.

распространяться по расчетной области со скоростью, меньшей, чем скорость ударной волны (рис. $2, c, d$ ).

Результаты наших расчетов, а также экспериментальные данные, описанные в работе [5], позволяют сделать вывод о существовании таких геометрических параметров препятствия, при которых возможно подавление детонации при минимальной его протяженности.

\section{Финансирование работы}

Исследование выполнено при финансовой поддержке Российского фонда фундаментальных исследований в рамках научного проекта № 20-38-90178.

\section{Конфликт интересов}

Авторы заявляют, что у них нет конфликта интересов.

\section{Список литературы}

[1] Д.А. Тропин, А.В. Федоров, Физика горения и взрыва, 55 (2), 119 (2019). DOI: 10.15372/FGV20190212

[2] D.A. Tropin, A.V. Fedorov, Combust. Sci. Technol., 191 (2), 275 (2019). DOI: 10.1080/00102202.2018.1459584

[3] А.А. Васильев, А.В. Пинаев, А.А. Трубицын, А.Ю. Грачев, А.В. Троцюк, П.А. Фомин, А.В. Трилис, Физика горения и взрыва, 53 (1), 11 (2017).

[4] B. Zhang, H. Liu, C. Wang, Int. J. Hydrogen Energy, 42 (33), 21392 (2017). DOI: 10.1016/j.ijhydene.2017.06.201

[5] A. Makris, A. Papyrin, M. Kamel, G. Kilambi, J.H.S. Lee, R. Knystautas, in Dynamic aspects of detonations, ed. by A.L. Kuhl, J.C. Leyer, A.A. Borisov, W.A. Sirignano. Progress in Astronautics and Aeronautics (AIAA, 1993), vol. 153, p. 363.

[6] P. Li, Q. Duan, L. Gong, K. Jin, J. Chen, J. Sun, Fuel, 236, 1586 (2019). DOI: 10.1016/j.fuel.2018.09.120
[7] D. Valiev, V. Bychkov, V. Akkerman, C.K. Law, L. Eriksson, Combust. Flame, 157 (5), 1012 (2010). DOI: 10.1016/j.combustflame.2009.12.021

[8] A.M. Coates, D.L. Mathias, B.J. Cantwell, Combust. Flame, 209, 278 (2019). DOI: 10.1016/j.combustflame.2019.07.044

[9] И.А. Бедарев, А.В. Федоров, Письма в ЖТФ, 42 (24), 17 (2016). DOI: $10.21883 /$ pjtf.2016.24.44074.16245

[10] И.А. Бедарев, К.В. Рылова, А.В. Федоров, Физика горения и взрыва, 51 (5), 22 (2015). DOI: 10.15372/FGV20150503

[11] F.R. Menter, AIAA J., 32 (8), 1598 (1994). DOI: $10.2514 / 3.12149$

[12] И.А. Бедарев, В.М. Темербеков, А.В. Федоров, Теплофизика и аэромеханика, 26 (1), 53 (2019). https://www.sibran.ru/ journals/issue.php?ID=177192\&ARTICLE_ID=177199 